\title{
Subthalamic Nucleus (STN) Deep-Brain Stimulation (DBS) in the Management of Idiopathic Parkinson's Disease: Results of our First 20 Cases
}

\author{
ESAM MOKBEL, M.D. and ESAM MOUNIR, M.D. \\ The Department of Neurosurgery, Faculty of Medicine, Tanta University
}

\begin{abstract}
Background: Idiopathic Parkinson's Disease (iPD) is one of the most disabling chronic neurologic diseases and leads to a significant loss of quality of life. Interest in surgical therapy for PD was renewed in the early 1990s. The most common functional stereotactic procedures that are performed worldwide for PD are lesioning and Deep-Brain Stimulation (DBS).
\end{abstract}

Aim of Study: Is to review and evaluate the results of STN-DBS in management of iPD in our first 20 patients.

Patients and Methods: This study was conducted in Department of Neurosurgery, Tanta University from January 2007 to March 2014. It included 20 patients with iPD, they must had positive L-dopa challenge test with at least a 33\% decrease in the UPDRS III score. All patients were assessed by UPDRS in off and on phases. Stereotactic STN-DBS was done. The total off UPDRS III score was considered the primary outcome measurement.

Results: We had 14 males and 6 females with a mean age at PD onset of 46.5 years, a mean age at implant of 54.5 years with mean duration of symptoms of 10 years. 14 patients had moderate PD while 6 patients had severe PD. The postoperative OFF and ON UPDRS III score improved by $45.5 \%$, and $63.9 \%$ respectively. The post-operative OFF and $\mathrm{ON}$ bradykinesia score improved by $55.5 \%$, and $62.9 \%$ respectively. The post-operative OFF and ON tremor score was improved by $68.01 \%$ and $76.5 \%$ respectively. The postoperative OFF and ON rigidity score was improved by $71.81 \%$ and $78.8 \%$. The post-operative OFF and ON postural instability and gait score was improved by $45.42 \%$ and $61.9 \%$ respectively. $60 \%$ of patients had good outcome and $40 \%$ had fair outcome. We reported one transient post-operative confusion, one infection, one lead displacement, and one lead fracture. Dyskinesia occurred in two patients, speech problems in two patients and emotional lability in one patient.

Conclusion: Bilateral STN-DBS provides significant symptom relief for the majority of well-screened patients with iPD.

Key Words: Stereotactic - Deep brain - Stimulation Parkinson.

Correspondence to: Dr. Esam Mokbel, The Department of Neurosurgery, Faculty of Medicine, Tanta University

\section{Introduction}

IDIOPATHIC Parkinson's Disease (iPD) is one of the most disabling chronic neurologic diseases and leads to a marked decrease of quality of life [1]. Although, advances in imaging modality, its diagnosis is mainly clinical. The diagnosis needs the presence of the following cardinal signs: Distal resting tremor, rigidity, bradykinesia, and asymmetrical onset $[2,3]$

Until the introduction of effective medical treatment with levodopa in 1967, surgical procedures were widely used in the treatement of PD patients. Surgery initially took the form of vascular, and then chemical lesions in the Globus Pallidus (GP) and later in thalamus [4].

The first surgeon to attempt lesioning of the basal ganglia was Meyers, in 1939, who ablated various parts of the caudate, putamen, and GP or its outflow tracts. The development of stereotactic pallidotomy and thalamotomy has been attributed to Cooper. The number of functional stereotactic operations, however, dropped rapidly with the appearance of levodopa in clinical routine $[5,6]$.

Pharmacological drugs was the main PD line of treatment during 1970s and 1980s, and surgery was nearly abandoned. Many drugs are available that can improve PD symptoms, but long term drugs therapy is usually accompanied by the appearance of levodopa-induced motor complications [7].

Surgical management of PD was renewed in the early 1990s. Many reasons attributed to this: First, failure of medical treatment of PD to arrest disease progression and its disabling side effects. Secondly, improved surgical and imaging tech- 
niques and a better understanding of basal ganglia physiology [8].

The most common functional stereotactic neurosurgical operations done all over the world for PD are lesioning and Deep-Brain Stimulation (DBS) of the three overactive nuclei (nucleus ventralis intermedius of the thalamus "VIM", the globus pallidus interna "GPi", and the subthalamic nucleus "STN") [9].

DBS is like other traditional functional neurosurgical ablative techniques in producing symptomatic relief without affecting the biology of the disease [10-12].

Hyperactivity of the STN is considered a hallmark of PD. The STN has many connections, including excitatory glutamatergic input directed at the GPi and substantia nigra. In experimental parkinsonism, modulation of STN activity showed therapeutic benefit [13]

In 1994 the first reports of bilateral STN-DBS in humans started to emerge, demonstrating improvement in all cardinal signs and symptoms of Parkinson's. Benabid et al., have followed more than 50 cases with STN DBS for 1 year who have maintained benefit [14]

DBS has gradually eliminated the practice of ablative procedures and provided dramatic improvement for many patients with advanced PD and complications of drug therapy [15]

Aim of work:

The aim of this study is to review and assess the results of STN-DBS and their efficacy in the surgical management of iPD in our first 20 patients.

\section{Patients and Methods}

This study was conducted in the Department of Neurosurgery at Tanta University from January 2007 to March 2014. It included 20 patients with iPD.

\section{Inclusion criteria:}

1- A clinical diagnosis of iPD which depended on:

- The presence of at least two cardinal signs of this disorder (bradykinesia, rest tremor, rigidity, and postural instability), but rest tremor or akinesia should present.

- Asymmetrical onset.

- Positive L-dopa challenge test to exclude Parkinson's plus syndrome, and also to show the expect- ed results anticipated from the surgery. The test should results in 33\% decrease in the Unified Parkinson's Disease Rating Scale part 3 (UPDRS III) score.

2- Hoehn and Yahr Scale Stage 3 or more when "OFF" medication [16]

3- Intractable disabling motor fluctuations or drug-induced dyskinesias.

\section{Exclusion criteria:}

1-Evidence of secondary or atypical parkinsonism.

2- MR images revealing evidence of significant brain atrophy.

3- Significant dementia or major psychiatric illness.

4- Significant medical disease that may increase risks of complications.

5- Chronic immunosuppression.

Pre-operative protocol:

Clinical aspect:

1- All patients were pre-operatively evaluated including detailed history taking, general examination and neurological examination.

2- All patients were evaluated on the clinical rating scales. We used UPDRS in off and on phases. The UPDRS consists of four primary parts to evaluate clinical problems accompanied PD:

- Part I: Behavior, cognition, mood, psychosis, and motivation scores (score 0-16);

- Part II: Activities of Daily Living (ADL) (score $0-52)$;

- Part III: Motor examination (score 0-108);

- Part IV: Additional complications of disease or therapy including dystonia, dyskinesia, and motor fluctuation estimates (score 0-23) [17].

The OFF phase means the condition of the patient after stopping antiparkinson drugs for 12 hours and being awake for at least 1 hour. The ON phase was the condition 1 hour after taking the usual first morning dose.

Investigative aspect:

1- The routine laboratory workup.

2- Pre-operative video recording (after written informed consent) in OFF and ON phases for analysis the movement disorder pattern and for documentation.

3- Pre-operative MRI on the brain. 


\section{Operative procedure:}

Stereotactic DBS was done for all patients. The targeting process was refined using intraoperative macroelectrode stimulation or macro stimulation based on Microelectrode Recording (MER). The STN was the target in all patients.

\section{Follow-up and outcome measures: \\ Clinical aspect:}

Post-operative clinical assessment was done, by a team consisting of: A neurosurgeon and a neurologist, every three months in standardized OFF and ON phases. Outcome measures included:

1- The UPDRS, especially the UPDRS motor sub score. The total off UPDRS III score was considered the primary outcome measurement. Based on the level of improvement in the total off UPDRS III score, a four graded system was used as the following:

- Excellent: $>75 \%$ improvement in the total off UPDRS III score.

- Good: $51-75 \%$ improvement in the total off UPDRS III score.

- Fair: $25-50 \%$ improvement in the total off UPDRS III score.

- Poor: $<25 \%$ improvement in the total off UPDRS III score.

2- Changes in the medications measured by LDopa equivalent dose (LED). To compare the effects of changes in antiparkinsonian drugs, we considered that a 100-mg of levodopa was equall to: $133 \mathrm{mg}$ of controlled-release levodopa; $75 \mathrm{mg}$ of levodopa plus entacapone; $1 \mathrm{mg}$ of pergolide, pramipexole, lisuride, or cabergoline; $5 \mathrm{mg}$ of ropinirole; $10 \mathrm{mg}$ of bromocriptine or apomorphine; and $20 \mathrm{mg}$ of dihydroergocriptine [18]

3-Adverse effects: Any new symptom or worsening of pre-existing symptom was reported as side effect. The patient was examined immediately after surgery, the first week after surgery, and then every three months.

\section{Investigative aspect:}

1- Immediate post-operative CT imaging for early detection of any complications and to estimate the accuracy for electrode placement.

2- Post-operative video recording (after written informed consent) in OFF and ON phases.

\section{Operative details:}

\section{Pre-operative preparation:}

All patients were admitted the day before surgery. All dopaminergic medications were stopped the night before or the morning of surgery, depending on the severity and quality of the patient's symptoms, to achieve a "practical OFF state" for intraoperative neurological testing.

Non-stereotactic MR imaging was performed 2 to 3 days before surgery. Thin-slice axial (2-mm slice thickness $\mathrm{T} 1$ and $\mathrm{T} 2$-weighted) and coronal images (T2-weighted) were obtained using a 1.5tesla scanner without inter-slice spacing.

Stereotactic imaging, target selection and trajectory planning:

The patient's head was fixed by placement in a modified Riechert-Mundinger stereotactic head ring (Inomed, Emmendingen, Germany) under local anesthesia. Ideal frame placement centered at the midline and parallel to the canthal-meatal line. The frame was mounted so that the base ring lies roughly parallel to the zygoma, which approximates parallel to the intercommissural line. Stereotactic cranial CT with IV contrast was performed using 2-mm slice thickness and no inter-slice spacing. The gantry angle kept at 0 degree. The CT data were transferred by an optical disk to the workstation. Multiplanar reconstruction software, Praezis plus 3 (Inomed Company, Germany) was used in every patient for planning and image fusion Fig. (1).

We preferred combining both direct and indirect targeting to give more accuracy. The STN was targeted on the basis of Schaltenbrand-Wahren atlas (SWA; Schaltenbrand \& Wahren, 1977) coordinates, using stereotactic cranial CT and stereotactic high resolution MRI (MRI; T1-and T2weighted) fusioned images, and also by determination of STN on T2-weighted MRI series. Our standard coordinates for targeting the dorsolateral part of the STN in patients with PD were $1.8 \mathrm{~mm}$ posterior to the mid AC (commissura anterior)-PC (commissura posterior) line (midcommissural point, $\mathrm{MCP}$ ), $3.8 \mathrm{~mm}$ ventrally to $\mathrm{MCP}$ and $12 \mathrm{~mm}$ laterally to midline. The trajectory taken to the target is as important as the target itself. In addition to the risk of damaging the internal capsule, lateral trajectories that do not pass through the thalamus and zona incerta provide limited MER data. The precise entry point was refined on the planning console such that the trajectory passed through the crown of a gyrus rather than into a sulcus to avoid damaging sulcal or pial vessels. The trajectory then was traced at millimeter intervals to ensure that no deep sulci or ventricular ependyma were transgressed Fig. (2). 


\section{Surgical technique:}

The patient's head in the frame was rigidly fixed to the operating table in a comfortable position. The patient was sedated with a short acting agent for this part of the operation. Long-acting benzodiazepines were avoided due to their effect on the neurophysiology. Because the patient must be quickly returned to an awake and cooperative state when needed, the use of narcotics was limited. We usually perform bilateral electrode implantations in a single setting.

Under local anesthesia, two curvilinear scalp incisions were. The scalp opening and burr hole creation were completed on the left side before moving the frame coordinates to the right side target and performing the entire procedure on that side. Once the first electrode was implanted, the frame was once again set to the left side target and microelectrode recording and lead placement was completed there. This allowed rapidly completing all the skull drilling that need heavy sedation and reducing the number of frame movements. The dura was coagulated and opened in a cruciate manner. The pia arachnoids were bipolar cauterized. A wide opening in the pia was then created with a \#11 blade to allow passage of the stimulating electrode. The stimulating electrode was inserted with a constant gentle rotating motion. Fibrin glue was used to seal the hole during each track to prevent cerebrospinal fluid escape and air entry.

The targeting process was refined using intraoperative macroelectrode stimulation with or without Microelectrode Recording (MER). Microelectrode recording was done in 10 patients. X-ray controls were regularly performed to check the accuracy of electrode insertion. Once the optimal target point resulting in best clinical improvement at lowest stimulation intensities had been defined, the testing electrode was replaced by the permanent quadripolar stimulating electrode (Model DBS 3389, Medtronic, Minneapolis, MN, 0.5-mm spacing between each of the four electrodes). The correct electrode position was finally documented in the Operative Room (OR) by using X-ray Fig. (3).

After insertion both of leads, the anesthesiologists may liberate sedation to make the patient comfortable. The head frame is removed in preparation for placement of the Implanted Pulse Generator (IPG).

Implantation of the IPG was done in the same day under general anesthesia. An infraclavicular subcutaneous pocket was created over the pectoralis fascia. The IPG was fixed to the fascia with two silk sutures to prevent migration and rotation. Any extra extension lead was coiled beneath the IPG. The connector should be seated over the occipital region rather than in the neck, where it could subjected to excessive torque, risking lead fracture. A multilayer closure of all incisions is performed.

\section{Post-operative care:}

The patients were monitored in the Intensive Care Unit overnight, restarted on all parkinsonian medications, and transferred to the neurosurgical ward on second day after. Antibiotics were continued for five days. Patients were discharged from the hospital on postoperative day two.

\section{DBS programming and reduction of medications:}

The stimulators were turned on at suture removal approximately 10 days after implantation. The stimulation parameters were definitively adapted by testing the effect of stimulation for each electrode pole in a monopolar mode under a controlled medication-OFF condition and by choosing the contact for long-term stimulation that gave the best clinical improvement at the lowest stimulation intensity and largest therapeutic range before induction of side effects. All parkinsonian medications were gradually withdrawn except levodopa was decreased till the optimum control of symptoms was achieved.

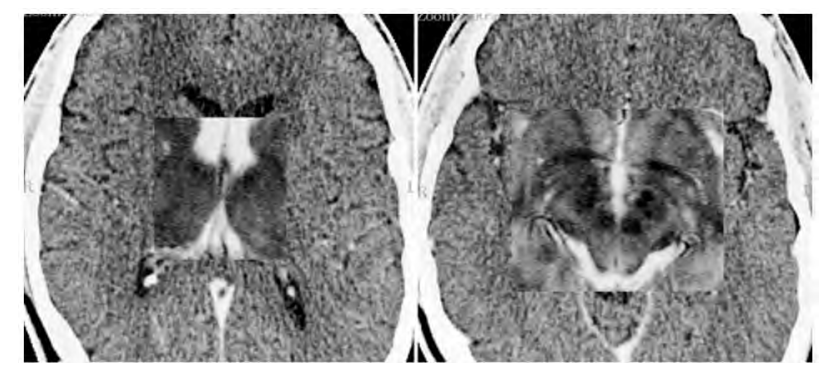

Fig. (1): Showing the value of CT-MR image fusion. The MR image is overlaid as a square on the stereotactic CT scan. Left: The MR imaging-defined ventricle contour fits perfectly with the ventricle contour shown on the CT scan. Right: Through image fusion the STN is visualized on T2-weighted images.
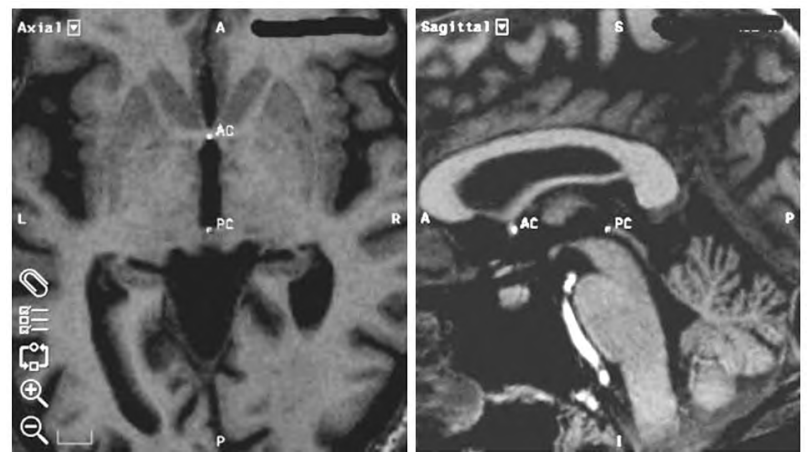

Fig. (2): T1-weighted MRI (axial \& sagittal) on the surgical planning station with the AC and PC marked. 

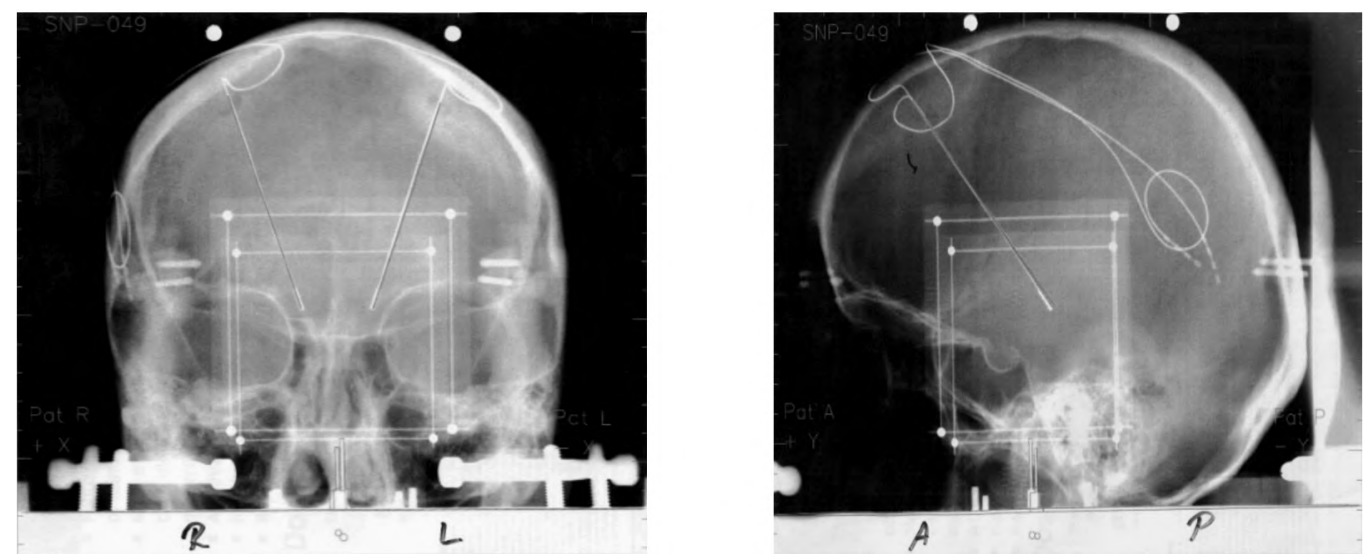

Fig. (3): The accuracy of the active electrode insertion was confirmed by intraoperative X-rays (anteroposterior and lateral).

\section{Adverse events:}

The adverse events were recorded. There are three types of complications related to DBS, namely related to surgery, device, and stimulation.

\section{Results}

A series of 20 patients with iPD treated with STN-DBS in The Department of Neurosurgery at Tanta University over more than seven years from January 2007 to March 2014.

All patients diagnosed as PD according to the UK Parkinson's disease Brain Bank criteria [19] and fulfilled the recommendations of the Core Assessment Program for Surgical Interventional Therapies in Parkinson's disease (CAPSIT-PD) panel [20]

We had 20 patients (14 males and 6 females) with idiopathic PD underwent bilateral stereotactic guided STN-DBS implants and received continuous stimulation for the subsequent years.

Patients had a mean age at PD onset of 46.5 years, a mean age at implant of 54.5 years with mean duration of symptoms of 10 years. Youngest age at STN DBS surgery was 29 years while the oldest was 70 years. The shortest duration of symptoms was 4 years. The longest duration of symptoms was 20 years (Table 1).

Table (1): Age and disease duration in 20 patients with PD.

\begin{tabular}{llll}
\hline Age and duration & \multicolumn{3}{c}{ Mini Maxi Mean } \\
\hline - Age at PD onset (years) & 18 & 62 & 46.5 \\
- Age at subthalamic nucleus DBS (years) & 29 & 70 & 54.5 \\
- Disease duration at subthalamic nucleus & 4 & 20 & 10 \\
DBS (years) & & & \\
\hline
\end{tabular}

Ten patients $(50 \%)$ had duration of symptoms of 6-10 years followed by 5 patients $(25 \%)$ had duration of symptoms of 11-15 years. Akineticrigid PD was found in $12(60 \%)$ patients followed by equivalent subtype in $6(30 \%)$ patients and the tremor-dominant PD in $2(10 \%)$ patients.

Before DBS, we had 14 patients (70\%) had moderate parkinson's disease (H \& Y Stage III) and 6 patients $(30 \%)$ had severe parkinson's disease (H \& Y Stage IV). After DBS patients with preoperative moderate parkinson's disease (stage III), $10 / 14$ patients $(71.43 \%)$ had minimal parkinsonian symptoms (stage I) while 4/14 patients $(28.57 \%)$ had mild parkinsonian symptoms (stage II) postoperatively. In patients with pre-operative severe Parkinson's disease (stage IV), 1/6 patients (16.67\%) had minimal parkinsonian symptoms (stage I), $3 / 6$ patients $(50 \%)$ had mild parkinsonian symptoms (stage II), and $2 / 6$ patients (33.33\%) had moderate parkinsonian symptoms (stage III) post-operatively (Table 2 ).

Table (2): Overall change in $\mathrm{H}$ and $\mathrm{Y}$ scale in 20 patients with PD operated upon.

\begin{tabular}{|c|c|c|c|c|c|c|}
\hline \multirow{3}{*}{$\begin{array}{l}\text { Pre- } \\
\text { operative } \\
\text { off phase } \\
\text { H \& Y } \\
\text { scale }\end{array}$} & \multirow{3}{*}{ Number } & \multirow{3}{*}{$\begin{array}{l}\text { Percent } \\
\%\end{array}$} & \multicolumn{4}{|c|}{$\begin{array}{l}\text { Post-operative off } \\
\text { phase H \& Y scale }\end{array}$} \\
\hline & & & \multicolumn{2}{|c|}{ Stage I } & Stage II & Stage III \\
\hline & & & No. & $\% \mathrm{I}$ & o. $\mathbf{o} / \mathbf{o}$ & No. $\mathbf{o} / \mathbf{o}$ \\
\hline Stage III & 14 & 70 & 10 & 71.43 & 428.57 & 0 \\
\hline Stage IV & 6 & 30 & 1 & 16.67 & 350 & 33.3 \\
\hline Total & 20 & 100 & 11 & 55 & 735 & 10 \\
\hline
\end{tabular}

The severity of motor manifestations measured by UPDRS III in 20 patients with PD. Mean preoperative OFF and ON medication total UPDRS III score was 50.89 and 21.74 respectively. Mean pre-operative OFF and ON medication bradykinesia score was 10.84 and 5.79. Mean pre-operative OFF and $\mathrm{ON}$ medication tremor score was 3.47 and 
1.66. Mean pre-operative OFF and ON medication rigidity score was 5.18 and1.84. Mean pre-operative OFF and ON medication postural instability and gait score was 5.46 and 1.68. The post-operative OFF and ON bradykinesia score improved by $55.5 \%$, and $62.9 \%$ respectively. The post-operative OFF and ON tremor score was improved by $68.01 \%$ and $76.5 \%$ respectively. The post-operative OFF and $\mathrm{ON}$ rigidity score was improved by $71.81 \%$ and $78.8 \%$. The post-operative OFF and ON postural instability \& gait score was improved by $45.42 \%$ and $61.9 \%$ respectively (Table 3 ).

Pre-operative L Dopa equivalent dose in $\mathrm{mg}$ (LED) and pre-operative UPDRS IV (complications of therapy). L-Dopa-equivalent daily dose (LED) was calculated according to recognized standard conversions [21]. Pre-operative minimum L-Dopa equivalent dose was $625 \mathrm{mg}$, while the maximum LED was $1998 \mathrm{mg}$. mean LED was $1270 \mathrm{mg}$. Preoperative mean L-Dopa induced dyskinesia score was 3.3, pre-operative mean off duration was 1.4 while the pre-operative mean total UPDRS IV (complications of therapy) was 8.2. Post-operative mean L-Dopa equivalent dose (LED) was reduced by $64.4 \%$. The mean post-operative UPDRS IV total score improved by $65.9 \%$. The mean postoperative L Dopa induced dyskinesia score improved by $83.6 \%$. The mean rate of improvement of off duration sub score was $71.4 \%$ (Table 4).

Table (3): Overall change in severity of parkinsonian symptoms measured by UPDRS III in 20 patients with PD operated upon.

\begin{tabular}{|c|c|c|c|c|c|c|c|}
\hline & \multicolumn{3}{|c|}{ Pre-operative score } & \multicolumn{3}{|c|}{ Post-operative score } & \multirow{2}{*}{$\%$} \\
\hline & Minimum & Maximum & Mean & Minimum & Maximum & Mean & \\
\hline \multicolumn{8}{|c|}{ Total UPDRS III score (0-108): } \\
\hline Off & 40 & 61 & 50.89 & 18 & 32 & 27.74 & 45.5 \\
\hline On & 17 & 30 & 21.74 & 6 & 14 & 7.84 & 63.9 \\
\hline \multicolumn{8}{|c|}{ Bradykinesia score (0-12): } \\
\hline Off & 8 & 13 & 10.84 & 3 & 8 & 4.82 & 55.5 \\
\hline On & 3 & 9 & 5.79 & 2 & 5 & 2.15 & 62.9 \\
\hline \multicolumn{8}{|c|}{ Tremor score $(0-28)$ : } \\
\hline Off & 2 & 7 & 3.47 & 1 & 3 & 1.11 & 68.01 \\
\hline On & 1 & 4 & 1.66 & 0 & 2 & 0.39 & 76.5 \\
\hline \multicolumn{8}{|c|}{ Rigidity score (0-20): } \\
\hline Off & 3 & 8 & 5.18 & 1 & 3 & 1.46 & 71.81 \\
\hline On & 0 & 4 & 1.84 & 0 & 1 & 0.39 & 78.8 \\
\hline \multicolumn{8}{|c|}{ Postural instability \& gait score (0-12): } \\
\hline Off & 2 & 8 & 5.46 & 1 & 5 & 2.98 & 45.42 \\
\hline On & 1 & 3 & 1.68 & 0 & 2 & 0.64 & 61.9 \\
\hline
\end{tabular}

Table (4): Overall change in L Dopa equivalent dose in mg (LED) and UPDRS IV (complications of therapy) in 20 patients with PD operated upon.

\begin{tabular}{|c|c|c|c|c|c|c|c|}
\hline \multirow{2}{*}{ LED \& UPDRS IV } & \multicolumn{3}{|c|}{ Pre-operative } & \multicolumn{3}{|c|}{ Post-operative } & \multirow{2}{*}{$\%$} \\
\hline & Mini & Max. & Mean & Mini & Max. & Mean & \\
\hline L Dopa equivalent dose in mg (LED) & 625 & 1998 & 1270 & 150 & 825 & 452.6 & 64.4 \\
\hline \multicolumn{8}{|l|}{ UPDRS IV (complications of therapy): } \\
\hline Total score (range $0-23$ ) & 6 & 13 & 8.2 & 2 & 7 & 2.8 & 65.9 \\
\hline L-Dopa induced dyskinesia score (items 32-34) & 2 & 7 & 3.3 & 0 & 2 & 0.54 & 83.6 \\
\hline Off duration (item 39) & 1 & 3 & 1.4 & 0 & 1 & 0.4 & 71.4 \\
\hline
\end{tabular}

Mean current amplitude used was $3.24 \mathrm{~V}$ (range $2-4.5 \mathrm{~V})$. Mean current frequency was $146.84 \mathrm{~Hz}$ (range 130-185Hz). Mean pulse width was $68.79 \mu \mathrm{s}$

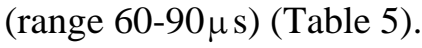

Pre-operative quality of life (activities of daily living) UPDRS-II was scored referring to the pa- tient's on and off conditions in the 4 weeks preceding the evaluation. The subscore for freezing of gait (item 14) was analyzed. Mean pre-operative off medication total UPDRS II score was 26.5 while the mean pre-operative on medication total UPDRS II score was 17.5. Mean pre-operative off medication freezing subscore was 2.1 while the 
mean pre-operative on medication freezing subscore was 1.4 .

The mean post-operative off UPDRS II score was 11.45 with the rate of improvement in off UPDRS II score was $56.79 \%$. The mean postoperative on UPDRS II score was 6.8 with the rate of improvement in on UPDRS II score was $61.4 \%$. The mean post-operative off freezing subscore was 0.8 with the rate of improvement in off freezing subscore was $61.9 \%$. The mean postoperative on freezing subscore was 0.4 with the rate of improvement in on freezing subscore was $71.42 \%$ (Table 6).

Table (5): Programming setting in 20 patients with PD.

\begin{tabular}{llll}
\hline & Mini. & Maxi. & Mean \\
\hline Current amplitude $(\mathrm{V})$ & 2 & 4.5 & 3.24 \\
Current frequency $(\mathrm{Hz})$ & 130 & 185 & 146.84 \\
Pulse width $(\mu \mathrm{s})$ & 60 & 90 & 68.79 \\
\hline
\end{tabular}

Table (6): Overall change in quality of life (UPDRS II).

\begin{tabular}{|c|c|c|c|c|c|c|c|}
\hline \multirow{2}{*}{$\begin{array}{l}\text { Activities of } \\
\text { daily living }\end{array}$} & \multicolumn{3}{|c|}{$\begin{array}{l}\text { Pre-operative } \\
\text { score }\end{array}$} & \multicolumn{3}{|c|}{$\begin{array}{l}\text { Post-operative } \\
\text { score }\end{array}$} & \multirow{2}{*}{$\%$} \\
\hline & Mini & $\operatorname{Max}$ & Mean & Mini & Max & Mean & \\
\hline \multicolumn{8}{|l|}{$\begin{array}{l}\text { Total UPDRS } \\
\text { II score }(0-52) \text { : }\end{array}$} \\
\hline Off & 17 & 36 & 26.5 & 18 & 32 & 11.45 & 56.79 \\
\hline On & 9 & 23 & 17.5 & 6 & 14 & 6.8 & 61.14 \\
\hline \multicolumn{8}{|l|}{$\begin{array}{l}\text { Freezing (item } \\
\text { 14): }\end{array}$} \\
\hline Off & 1 & 3 & 2.1 & 0 & 2 & 0.8 & 61.9 \\
\hline On & 0 & 2 & 1.4 & 0 & 1 & 0.4 & 71.42 \\
\hline
\end{tabular}

We had $12 / 20$ patients $(60 \%)$ had good outcome and $8 / 20$ patients had fair outcome. There were no cases that exhibited excellent or poor outcome.

Regarding the complications, one patient (5\%) had transient post-operative confusion and hallucinations. There was one device-related infection (internal pulse generator removal was done and replaced after 6 months with new one). Lead displacement occurred in one patient (need revision), and lead fracture in one patient (need replacement) (Table 7).

Table (7): Surgery and device related complications in 20 patients.

\begin{tabular}{lccl}
\hline Complications & No. & $\%$ & Notes \\
\hline Surgery related: & & & \\
$\quad$ Confusion & 1 & 5 & Transit \\
Device related: & & & \\
$\quad$ Infection & 1 & 5 & Required hospitalization \\
$\quad$ Lead displacement & 1 & 5 & and surgery \\
$\quad$ Lead fracture & 1 & 5 & \\
\hline
\end{tabular}

Stimulation-induced dyskinesia occurred in two patients which required adjustment of stimulation parameters and reduction of dopaminergic medication. Speech problems were seen in two patients and seemed to be caused by excessive stimulation of the corticobulbospinal tract located laterally. These speech problems were transit and required stimulation parameters adjustment. Emotional lability problems were seen in one patient (Table 8).

Table (8): Stimulation related complications.

\begin{tabular}{lccl}
\hline Stimulation related complications & No. & $\%$ & Notes \\
\hline Disabling stimulation-induced dyskinesia. & 2 & 10 & Transit, required stimulation adjustment. \\
Speech problems (worsening of hypophonia, dysarthria). & 2 & 10 & Transit. required stimulation adjustment. \\
Emotional lability (depression, anxiety, hypomania). & 1 & 5 & Transit. required psychiatric treatment. \\
\hline
\end{tabular}

\section{Discussion}

DBS is now considered as an adjunct management for PD. It is recommended for patients with intractable tremor or who are suffered from complications of L-dopa as motor fluctuations and severe dyskinesias. The DBS procedure contrary to ablative surgery has the unique advantage of being reversible and adjustable over time [9-12].

All patients in this study underwent bilateral STN-DBS. This technique is now considered better than GPi-DBS as it has provided significant improvement of the motor conditions of patients with motor fluctuations and dyskinesias, and has allowed to reduce antiparkinsonian medication. Moreover STN-DBS has allowed the possibility to also influence the subthalamic region (which contains pallidofugal fibres) and lower energy consumption $[22,23]$. Thalamic stimulation in Vim gives significant decreases of tremor without any effect on other symptoms of Parkinson's disease [24]

The most important step in successful DBS remains attention to selecting the appropriate patient. A multi-disciplinary approach (neurologist, neurosurgeon, neuropsychologist, and psychiatrist) is the best and safest method for selecting DBS 
patients. In our study, the assessments are performed by experienced DBS teams and the results of individual evaluations are discussed in a multidisciplinary team meeting prior to proceeding with surgery [22-24]

In our study, positive clinical outcome was not associated with age or gender. The majority of centers have arbitrarily utilized an upper age limit of 75 years but there is no consensus on what a safe upper age limit should be for DBS surgery. Russmann et al., [25] showed that patients over 70 years old had worsening of UPDRS motor score after STN-DBS. So it is possible that older patients benefit to a lesser extent than younger ones. Moreover, older patients might also tolerate surgery less because of the co-morbidities, and they might be at a higher risk for mental deterioration after STNDBS [26]. We did not report that our older STNDBS patients did less well although the mean age was 54.5 years. It is recommended that patients older than 70 should be evaluated individually and consideration for the level of disability, degree of expected improvement, presence of medical comorbidities, life expectancy, cognition, and the ability to satisfactorily meet the operative and postoperative requirement of surgery should all be weighed rather than age alone.

Another important consideration in patient selection for DBS is the duration of parkinsonian symptoms. In our study, mean duration of symptoms was 10 years (ranged from 4 to 20 years). The preferable situation is to consider patients candidates only if they have disease duration of 5 years or more. Waiting for 5 years aids in identifying other atypical parkinsonian syndromes. It will differentiate and display levodopaunresponsive symptoms, autonomic and cognitive dysfunction as well other features that may further distinguish the symptoms as not a pure Parkinson's disease [27]

Timing of surgery has been a controversy since the efficacy of STN-DBS is widely recognized. The established approach is to offer surgery to patients only when medical therapy has failed as the risk of surgery may only be justified under such circumstances. Despite this prevailing view, Kleiner-Fisman et al., [28] has revealed that patients with milder disease (as determined by lower baseline UPDRS III medication off scores) were increasingly being operated upon in studies published after 2002. Charles et al., [29] concluded that DBS is well tolerated in early PD. They suggested that DBS is becoming a more accepted treatment modality and being considered earlier in the course of PD. The possible merits of early surgery are to avoid disability and prevent loss of employment.

The success of DBS for PD depends largely on accuracy in target determination. The accuracy of target localization can be influenced by many items, as choice and mounting of stereotactic frames, imaging modality and method of image-based targeting, and use of electrophysiological methodologies. Some centers use a CT scan [30], while others use a MRI [31] or a combination of both [32]. The potential benefits of CT include faster scan times, less expensive equipment, and no distortion of images. Its disadvantages are poorer anatomic detail including grey-white differentiation. The potential benefits of MRI include enhanced anatomic detail, easier visualization of the intercommissural line in the sagittal plane, and better grey-white matter differentiation. It is possible to visualize and directly target the STN. However, it can be difficult to differentiate the STN from the substantia nigra. The disadvantages of MRI include image distortion, long scanning times, and the other standard contraindications for MRI [33]. We used CT/MRI based indirect targeting. Regarding these points, the fusion of pre-operative MR images with stereotactic CT scans has some advantages: 1) The stereotactic MR data set that is created by the fusion process, displays a high spatial accuracy; 2) The patient/object-related distortion of MR imaging is nearly corrected; and a more practical aspect is that 3) MR-based stereotaxy is possible, even at institutions in which an MR Unit is not located close to or inside the OR. Non stereotactic MR imaging was performed 2 to 3 days before surgery. The data obtained from MR images were integrated into the 3D stereotactic coordinate system by using landmark-based image fusion.

Also, the targeting process was refined using intraoperative macroelectrode stimulation or macrostimulation based on Microelectrode Recording (MER). Microelectrode recording was done in 10 patients. MER was used when MRI scans were not enough to see the target due to the nuclear boundaries were indistinct or when MER was the method of choice to the neurosurgeon. MER appears to provide a patient-specific physiological map that may not only be more anatomically accurate than image-based targeting, but that also may be more functionally relevant for final target determination and provide better definition of vital structures to be avoided. Most current literature supports microelectrode refinement in targeting deep brain structures for movement disorder surgery [34]. Numerous other studies have reported that MER changed the final target in most or all cases, regardless of choice 
of deep brain target and regardless of whether lesioning or stimulation was employed $[35,36]$ However, MER is time-consuming and therefore contributes to some patient discomfort. There is also a theoretical but uncertain more risk of bleeding following use of multiple recording tracts. No study clearly proved that MER gives better results, the use of MER in clinical practice is still questionable. It has been concluded that direct visual targeting or atlas/coordinate-based methods may give good accuracy alone if imaging errors can be minimized [33].

The mean current amplitude used for therapeutic stimulation was $3.24 \mathrm{~V}$ (range $2-4.5 \mathrm{~V}$ ). Mean current frequency was $146.84 \mathrm{~Hz}$ (range $130-185 \mathrm{~Hz}$ ). Mean pulse width was 68.79 (1) Typically, a pulse width of 60-120 s isused in DBS. Changing stimulation pulse width can alter the neural elements affected by DBS-longer pulse width has a greater effect on cell soma while shorter pulse width preferentially affects axons [37]. The most commonly reported frequencies for STN were $130 \mathrm{~Hz}$ and $185 \mathrm{~Hz}$. Increasing stimulation frequency does not increase current spread, but does reduce battery life. Therefore, for STN stimulation $130 \mathrm{~Hz}$ is used initially and frequency is only increased to $185 \mathrm{~Hz}$ if suboptimal benefit is achieved and an increase in pulse width or amplitude results in adverse effects due to current spread [18].

We used the motor UPDRS III as a primary outcome measure for assessment of clinical improvement because this measure is most commonly reported in the published literature. UPDRS Part III is based on a neurological examination, and needs observation of the patient sitting quietly at rest, doing movements, standing, walking and in response to challenged postural reflexes [17]. Consistent with many studies, we reported marked improvement by $45.5 \%$ in ON stimulation/OFF medication UPDRS III scores. Although there was evident heterogeneity between studies, on average patients improved by approximately $52 \%$ over baseline UPDRS III off scores [28]. Our patients improved by approximately $64 \%$. In ON stimulation/ON medication UPDRS III scores. Hamani et al., [38] reported $71 \%$ improvement in ON stimulation/ON medication UPDRS III scores compared to pre-operative off state after 6 months. This improvement declined to $69 \%$ after 12 months and $65 \%$ after 24 months respectively. We reported that, the rate of improvement in OFF bradykinesia score was $55.5 \%$ while the rate of improvement in ON bradykinesia score was $62.9 \%$. Limousin et al., [39] reported a 56\% improvement in akinesia after STN DBS in response to stimulation alone, but noted a $12 \%$ worsening in akinesia scores when patients were tested with both stimulation and LDopa. Other reports documented improvements in akinesia that range from $25 \%$ to $71 \%$ [40]

In our study, the rate of improvement in OFF tremor score was approximately $68 \%$ while the rate of improvement in ON tremor score was $76.5 \%$. This is consistent with other studies that reported 74-79\% reduction in total tremor score [41,42]. We found $45.5 \%$ improvement in OFF postural instability \& gait score while the rate of improvement in ON postural instability \& gait score was approximately $62 \%$. In agreement with our results, Fasano and colleagues [43] reported lower rate of postural instability at 5 and 8 years from surgery. The positive effects of STN-DBS on balance and postural stability, which was reported by most authors, may be due to the improvement of rigidity and bradykinesia, rather than on a specific effect on balance and gait. In comparison with our data, St George et al., [44] concluded that postural instability and gait disability increase by time in patients subjected to STN-DBS. The long-term results of STN-DBS clinical researches, showed some sort of difference that may be explained by many reasons, such as disease duration at the time of surgery and age at PD onset. This may be also due to different disease mechanisms with the involvement of non-dopaminergic systems as well as other cerebral regions, for example, the pedunculopontine [38].

After STN-DBS, there was a marked decrease of medications. Post-operative mean LED dose was reduced by $64.4 \%$ after STN DBS. Most of literature recorded post-operative decrease of medication LED dose or even suspending antiparkinsonian medication, which is not usually reported with pallidotomy or pallidal DBS [45] Some reports showed that it is not established yet whether this difference results from the superiority of the STN target or is at least partly due to possible bias in the selection or post-operative management of the patients [46]. We found improvement of drugrelated motor complications, namely off periods and dyskinesias, which was well maintained over time together with a prolonged decrease of dopaminergic drugs dose. The mean rate of improvement of post-operative L-dopa induced dyskinesia score was $83.6 \%$ while the mean rate of improvement of off duration sub score was $71.4 \%$. This is consistent with other studies that reported $76.9 \pm 12.6 \%$ (range: $58-91 \%$ ) reduction in $\mathrm{ON}$ medication-ON stimulation dyskinesia severity for STN DBS $[18,47,48]$. Our results showed that the ADL were also improved by STN-DBS in the long- 
term follow-up. The rate of improvement in OFF $\&$ ON UPDRS II score was $56.79 \%, 61.4 \%$, and rate of improvement in OFF \& ON freezing subscore was $61.9 \%, 71.42 \%$ respectively. This is consistent with other studies that reported $50 \%$ improvement in ADL scores after surgery [28] Zibetti et al., [49] reported that UPDRS-II OFF score improved $66 \%$ at 1 year and $47 \%$ at 5 years. OFF state freezing of gait score improved at 1 year, but no longer at 5 years with respect to baseline. UPDRS-II score in the ON condition, did not vary significantly 1 and 5 years after surgery with respect to baseline. ON period freezing of gait score showed no difference 1 and 5 year postoperatively. The efficacy of STN-DBS was defined as the post-operative percentage of improvement of UPDRS-III total score from baseline. $60 \%$ of our patients had good outcome while $40 \%$ of our patients had fair outcome.

Generally, none of our patients had a major or life threatening complication. Operative complications were noted in $20 \%$ of our patients. In terms of hardware related complications, we had devicerelated infection in one case which was severe infection so we had to remove the IPG and replaced after 6 months with new one. Lead displacement was detected in one patients (revision surgery was done) while lead fracture reported in one patient (lead replacement was done). The reported rate of device-related complications showed great difference between centers. A systemic review of the clinical literature evaluated a total of 737 PD patients treated with bilateral STN DBS; mortality was $0.4 \%$. The incidence of Intracranial Hemorrhage (ICH) was $2.8 \%$, and caused permanent neurological deficits in $1 \%$ of patients. Other frequently observed problems were: Seizures $(0.9 \%)$, pulmonary embolism $(0.5 \%)$, meningitis $(0.1 \%)$, and CSF leakage $(0.1 \%)$. The implanted leads gave rise to problems (migration, breakage) in $4.5 \%$ of cases. Infection of the hardware $(3.4 \%)$ required removal of the system in $1.8 \%$ of patients [50]. Most hardware problems, however, occurred in the first patients of a series and were less frequent afterward. This may be due to the sophisticated nature of the surgery, that need good training before doing DBS surgery. We had one case (5\%) of postoperative transient confusion and hallucinations. The most frequent side effects recorded in the literature after bilateral STN-DBS were perioperative confusion and psychiatric problems which are often transient and may due to withdrawal or decrease of L-dopa in the perioperative period [51] Some problems with the STN-DBS come from the complex interactions of drugs and stimulation. One of the challenges in the follow-up management is to differentiate between genuine stimulationinduced side effects and preexisting symptoms of PD that are uncovered by a combination of decreased dopaminergic drugs and inadequate stimulation effects [24]. In our study, stimulationinduced dyskinesia occurred in two patients. Stimulation of the STN may induce dyskinesia/ dystonia in the early period after surgery. However, stimulation-induced dyskinesia in STN-DBS seems to indicate correct electrode placement. Therefore, a favorable outcome can be expected by careful adjustment of stimulation and drastic decrease of dopaminergic drugs. Speech problems were seen in two patients in our study which were transit and required stimulation parameters adjustment. Stimulation-induced dysarthria is caused by excessive stimulation of the corticobulbospinal tract located laterally to the STN. Therefore, dysarthria is inevitable with the increase of stimulation power. In such cases, changing stimulation parameters is effective in most patients. As the effect on cardinal PD symptoms may decrease with changing stimulation parameters, a balance between expected result of DBS and adverse effect of dysarthria should be achieved by determining the patient's satisfaction level. Dysarthria in the early postoperative period may be a defect of verbal fluency, due to cognitive sequela. But, dysarthria in the later period may be caused by disease progression

Emotional lability problems were seen in one patient treated with STN-DBS in our study. Mania was usually transient and appeared early after surgery. Depression was treated by more dose of the dopaminergic treatment. Depression and other mood changes are frequent complications and usually transient in the early post-operative period [53].The spread of stimulation to the limbic STN may explain the changes of mood [54]. Excessive decrease of dopaminergic drugs in the first months after surgery can lead to apathy and depression and can be treated by increasing the dose again. Severe depression after STN-DBS was recorded, so great attention should be taken regarding patient's mental state. Suicidal attacks are the most common cause of death during first year after STN-DBS [53] . Surgery-related and device-related complications can be decreased by training and introduction of new technology. Treatment-related side effects can be due to stimulation effect or excessive decrease of dopaminergic medication after surgery or progression of disease. Physicians engaged in this treatment should have a comprehensive grasp of the probable complications and how to avoid them. 


\section{Conclusion:}

Bilateral STN-DBS gives marked improvement of symptoms for most of good selected patients with iPD. Bilateral implantation of stimulating electrodes in the same sitting has become standard worldwide. DBS done on the right patient by an experienced team can give a lot of benefits that cannot be achieved with drugs alone.

\section{References}

1- SCHRAG A., JAHANSHAHI M. and QUINN N.: What contributes to quality of life in patients with Parkinson's disease? J. Neurol. Neurosurg. Psychiatry, 69: 308-12, 2000.

2- NUTT J.G. and WOOTEN G.F.: Clinical practice. Diagnosis and initial management of Parkinson's disease. N. Engl. J. Med., 353: 1021-7, 2005.

3- SUCHOWERSKY O., REICH S., PERLMUTTER J., ZESIEWICZ T., GRONSETH G. and WEINER W.J.:

Practice parameter: Diagnosis and prognosis of new onset Parkinson disease (an evidence-based review): Report of the Quality Standards Subcommittee of the American Academy of Neurology. Neurology, 66: 968-75, 2006.

4- OLANOW C.W.: Surgical therapy for Parkinson's disease. Eur. J. Neurol., 9 (3): 31-9, 2002.

5- KRAUSS J.K. and GROSSMAN R.G.: Historical review of pallidal surgery for treatment of Parkinsonism and other movement disorders. In: Krauss JK, Grossman RG, Jankovic J, eds. Pallidal surgery for the treatment of Parkinson's disease and movement disorders. Philadelphia: Lippincott Raven, 1-23, 1998.

6- GILDENBERG P.L.: The history of stereotactic and functional neurosurgery. In: Gildenberg, P.L., Tasker, R, R. eds. Textbook of stereotactic and functional neurosurgery. New York. McGraw-Hill. 5-19, 1998.

7- GOETZ C.G., POEWE W., RASCOL O. and SAMPAIO C.: Evidence-based medical review update: Pharmacological and surgical treatments of Parkinson's disease: 2001 to 2004. Mov. Disord., 20: 523-39, 2005.

8- MARSDEN C.D. and OBESO J.A.: The functions of the basal ganglia and the paradox of stereotaxic surgery in Parkinson's disease. Brain, 117 (4): 877-97, 1994.

9- QUINN N.: Progress in functional neurosurgery for Parkinson's disease. Lancet, 354 (9191): 1658-9, 1999.

10- GILL S.S., PATEL N.K. and HOTTON G.R.: Direct brain infusion of glial cell line-derived neurotrophic factor in Parkinson disease. Nat. Med., 9: 589-95, 2003.

11- PATEL N.K., BUNNAGE M. and PLAHA P.: Intraputamenal infusion of glial cell line-derived neurotrophic factor in PD; a two-year outcome study. Ann. Neurol., 57: 298-302, 2005.

12- DURING M.J., KAPLITT M.G. and STERN M.B.: Subthalamic GAD gene transfer in Parkinson disease patients which are candidates for deep brain stimulation. Hum. Gene Ther., 12: 1580-9, 2001.

13- LUO J., KAPLITT M.G. and FITZSIMONS H.L.: Subthalamic GAD gene therapy in a Parkinson's disease rat model. Science, 298: 425-9, 2002.
14- BENABID A.L., POLLAK P., GROSS C., HOFFMANN D., BENAZZOUZ A., GAO D.M., LAURENT A., GENTIL A. and PERRET J.: Acute and long-term effects of subthalamic nucleus stimulation in Parkinson's disease. Stereotact Funct Neurosurg., 62: 76-84, 1994.

15- DEUSCHL G., SCHADE-BRITTINGER C., KRACK P., VOLKMANN J., SCHÄFER H., BÖTZEL K., et al.: A randomized trial of deep-brain stimulation for Parkinson's disease. N. Engl. J. Med., 355: 896-908, 2006.

16- HOEHN M.M. and YAHR M.D.: Parkinsonism: Onset, progression, and mortality. Neurology, 17: 427-42, 1967.

17- FAHN S., MARSDEN C.D., CALNE D.B. and GOLDSTEIN M.: Recent Developments in Parkinson's Disease. 2: 153-163 Macmillan Healthcare Information Florham Park, N.J. 293-304, 1987.

18- HERZOG J., VOLKMANN J., KRACK P., KOPPER F., PÖTTER M., LORENZ D., et al.: Two-year follow-up of subthalamic deep brain stimulation in Parkinson's disease. Mov. Disord., 18 (11): 1332-7, 2003.

19- HUGHES A.J.1., DANIEL S.E., KILFORD L. and LEES A.J.: Accuracy of clinical diagnosis of idiopathic Parkinson's disease: A clinicopathological study of 100 cases, J. Neurol. Neurosurg. Psychiatry, 55: 181-4, 1992.

20- DEFER G.L., WIDNER H., MARIÉ R.M., RÉMY P. and LEVIVIER M.: Core assessment program for surgical interventional therapies in Parkinson's disease (CAPSITPD). Mov. Disord., 14 (4): 572-84, 1999.

21- TOMLINSON C.L., STOWE R., PATEL S., RICK C., GRAY R. and CLARKE C.E.: Systematic review of levodopa dose equivalency reporting in Parkinson's disease. Mov. Disord., 25: 2649-53, 2010.

22- ANDERSON V.C., BURCHIEL K.J., HOGARTH P., FAVRE J. and HAMMERSTAD J.P.: Pallidal versus subthalamic nucleus deep brain stimulation in Parkinson disease. Arch. Neurol., 62: 554-60, 2005.

23- LIMOUSIN P. and MARTINEZ-TORRES I.: Deep brain stimulation for Parkinson's disease. Neurotherapeutics, 5: 309-19, 2008.

24- VOLKMANN J.: Deep brain stimulation for the treatment of Parkinson's disease. J. Clin. Neurophysiol., 21 (1): 617, 2004.

25- RUSSMANN H., GHIKA J., VILLEMURE J.G., ROBERT B., BOGOUSSLAVSKY J., BURKHARD P.R. and VINGERHOETS F.J.: Subthalamic nucleus deep brain stimulation in Parkinson disease patients over age 70 years. Neurology, 23; 63 (10): 1952-4, 2004.

26- SAINT-CYR J.A., TREPANIER L.L., KUMAR R., LOZANO A.M. and LANG A.E.: Neuropsychological consequences of chronic bilateral stimulation of the subthalamic nucleus in Parkinson's disease. Brain, 123: 2091-108, 2000.

27- MIYASAKI J.M., SHANNON K., VOON V., RAVINA B., KLEINER-FISMAN G., ANDERSON K., et al.: Practice Parameter: Evaluation and treatment of depression, psychosis, and dementia in Parkinson disease (an evidencebased review): Report of the Quality Standards Subcommittee of the American Academy of Neurology. Neurology, 66 (7): 996-1002, 2006.

28- KLEINER-FISMAN G., HERZOG J., FISMAN D.N., TAMMA F., LYONS K.E., PAHWA R., LANG A.E. and 
DEUSCHL G.: Subthalamic nucleus deep brain stimulation: Summary and meta-analysis of outcomes. Mov. Disord., (14): 290-304, 2006.

29- CHARLES D., KONRAD P.E., NEIMAT J.S., MOLINARI A.L., TRAMONTANA M.G., FINDER S.G., et al.: Subthalamic nucleus deep brain stimulation in early stage Parkinson's disease. Parkinsonism. Relat. Disord., 20 (7): 731-7, 2014.

30- SAMUEL M., CAPUTO E., BROOKS D.J., SCHRAG A., SCARAVILLI T., BRANSTON N.M., et al.: A study of medial pallidotomy for Parkinson's disease: Clinical outcome, MRI location and complications. Brain, 121 (1): 59-75, 1998.

31- VITEK J.L., BAKAY R.A., HASHIMOTO T., KANEOKE Y., MEWES K., ZHANG J.Y., et al.: Microelectrodeguided pallidotomy: Technical approach and its application in medically intractable Parkinson's disease. J. Neurosurg., 88 (6): 1027-43, 1998.

32- IACOPINO D.G., CONTI A., ANGILERI F.F. and TOMASELLO F.: Different methods for anatomical targeting. J. Neurosurg. Sci., 47 (1): 18-25, 2003.

33- GILLER C.A., DEWEY R.B., GINSBURG M.I., MENDELSOHN D.B. and BERK A.M.: Stereotactic pallidotomy and thalamotomy using individual variations of anatomic landmarks for localization. Neurosurgery, 42 (1): 56-62; discussion 62-5, 1998.

34- ZONENSHAYN M., REZAI A.R., MOGILNER A.Y., BERIC A., STERIO D. and KELLY P.J.: Comparison of anatomic and neurophysiological methods for subthalamic nucleus targeting. Neurosurgery, 47 (2): 282-92; discussion 292-4, 2000.

35- FORSTER A., ELJAMEL M.S., VARMA T.R., TULLEY M. and LATIMER M.: Audit of neurophysiological recording during movement disorder surgery. Stereotact. Funct. Neurosurg., 72 (2-4): 154-6, 1999.

36- BEJJANI B.P., DORMONT D., PIDOUX B., YELNIK J., DAMIER P., ARNULF I., et al.: Bilateral subthalamic stimulation for Parkinson's disease by using threedimensional stereotactic magnetic resonance imaging and electrophysiological guidance. J. Neurosurg., 92 (4): 615$25,2000$.

37- RANCK J.B.: Which elements are excited in electrical stimulation of mammalian central nervous system? A review. Brain Res., 98: 417-40, 1975.

38- HAMANI C., RICHTER E.O., SCHWALB J.M. and LOZANO A.M.: Bilateral subthalamic nucleus stimulation for Parkinson's disease: A systematic review of the clinical literature. Neurosurgery, 56: 1313-24, 2005.

39- LIMOUSIN P., KRACK P., POLLAK P., BENAZZOUZ A., ARDOUIN C., HOFFMANN D. and BENABID A.L.: Electrical stimulation of the subthalamic nucleus in advanced Parkinson's disease. N. Engl. J. Med., 339: 1105$11,1998$.

40- RIZZONE M.G., FASANO A., DANIELE A., ZIBETTI M., MEROLA A., RIZZI L., et al.: Long-term outcome of subthalamic nucleus DBS in Parkinson's disease: From the advanced phase towards the late stage of the disease? Parkinsonism. Relat. Disord., 20 (4): 376-81, 2014.
41- RODRIGUEZ M.C., GURIDI O.J., ALVAREZ L., MEWES K., MACIAS R., VITEK J., et al.: The subthalamic nucleus and tremor in Parkinson's disease. Mov. Disord., 13 (3): 111-8, 1998.

42- BURCHIEL K.J., ANDERSON V.C., FAVRE J. and HAMMERSTAD J.P.: Comparison of pallidal and subthalamic nucleus deep brain stimulation for advanced Parkinson's disease: Results of a randomized, blinded pilot study. Neurosurgery, 45 (6): 1375-82; discussion 1382-4, 1999.

43- FASANO A., ROMITO L.M., DANIELE A., PIANO C., ZINNO M., BENTIVOGLIO A.R. and ALBANESE A.: Motor and cognitive outcome in patients with Parkinson's disease 8 years after subthalamic implants. Brain, 133: 2664-76, 2010.

44- ST GEORGE R.J., NUTT J.G., BURCHIEL K.J. and HORAK F.B.: A meta-regression of the long-term effects of deep brain stimulation on balance and gait in Parkinson's disease. Neurology, 75: 1292-9, 2010.

45- VITEK J.L.: Deep brain stimulation for Parkinson's disease. A critical re-evaluation of STN versus GPi DBS. Stereotact. Funct. Neurosurg., 78 (3-4): 119-31, 2002.

46- MINGUEZ-CASTELLANOS A., ESCAMILLASEVILLA F., KATATI M.J., MARTIN-LINARES J.M., MEERSMANS M., ORTEGA-MORENO A. and ARJONA V.: Different patterns of medication change after subthalamic or pallidal stimulation for Parkinson's disease: Target related effect or selection bias? J. Neurol. Neurosurg. Psychiatry, 76 (1): 34-9, 2005.

47- KRAUSE M., FOGEL W., HECK A., HACKE W., BONSANTO M., TRENKWALDER C. and TRONNIER V.: Deep brain stimulation for the treatment of Parkinson's disease: Subthalamic nucleus versus globus pallidus internus. J. Neurol. Neurosurg. Psychiatry., 70: 464-70, 2001.

48- VESPER J., KLOSTERMANN F., STOCKHAMMER F. FUNK T. and BROCKM: Results of chronic subthalamic stimulation for Parkinson's disease: A 1- year follow-up study. Surg. Neurol., 57: 311-3, 2002.

49- ZIBETTI M., MEROLA A., RIZZI L., RICCHI V., ANGRISANO S., AZZARO C., et al.: Beyond nine years of continuous subthalamic nucleus deep brain stimulation in Parkinson's disease. Mov. Disord., 26 (13): 2327-34, 2011.

50- HAMANI C., RICHTER E.O., SCHWALB J.M. and LOZANO A.M.: Bilateral subthalamic nucleus stimulation for Parkinson's disease: A systematic review of the clinical literature. Neurosurgery, 56: 1313-24, 2005.

51- LANG A.E., KLEINER-FISMAN G., SAINT-CYR J.A., MIYASAKI J. and LOZANO A.: Subthalamic DBS replaces levodopa in Parkinson's disease: Two-year followup. Neurology, 14; 60 (1): 154-5; author reply 154-5, 2003.

52- UMEMURA A., OKA Y., YAMAMOTO K., OKITA K., MATSUKAWA N. and YAMADA K.: Complications of subthalamic nucleus stimulation in Parkinson's disease. Neurol. Med. Chir. (Tokyo), 51 (11): 749-55, 2011.

53- VOON V., KRACK P., LANG A.E., LOZANO A.M., DUJARDIN K., SCHÄUPBACH M., et al.: A multicentre study on suicide outcomes following sub- thalamic stimulation for Parkinson's disease. Brain, 131: 2720-8, 2008. 
54- MALLET L. SCHÄUPBACH M., N' DIAYE K., REMY

P., BARDINET E., CZERNECKI V., et al.: Stimulation of subterritories of the subthalamic nucleus reveals its role in the integration of the emotional and motor aspects of behavior. Proc. Natl. Acad. Sci. USA, 104: 10661-6, 2007.

\section{تحفيز المخ العميق لنواة تحت المهاد

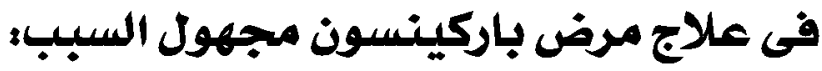

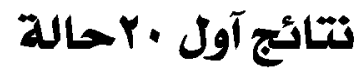

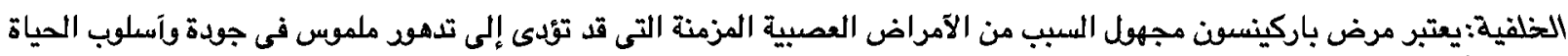

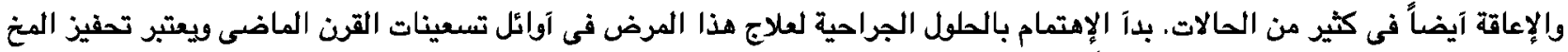

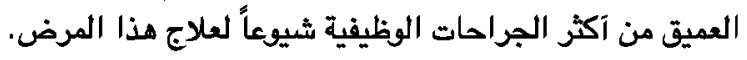

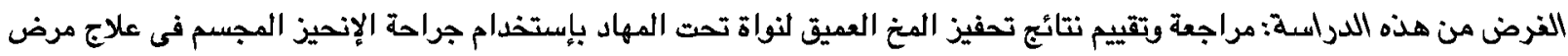

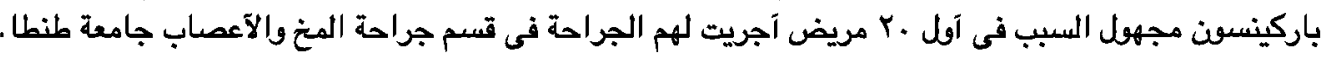

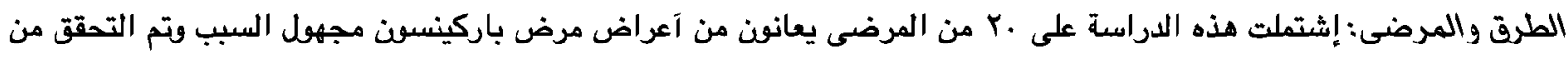

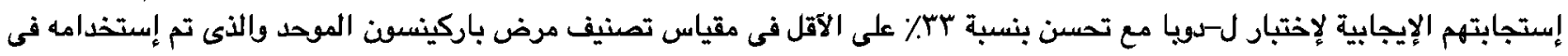

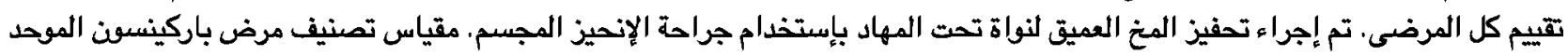
الجزء الثالث تم إعتباره المقياس الآولى لتقييم النتائج.

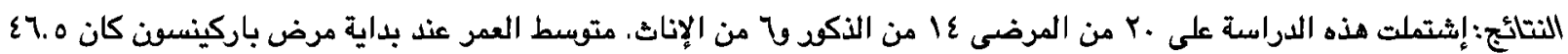

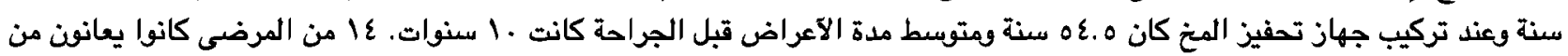

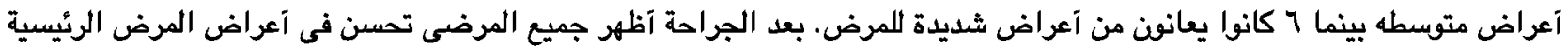

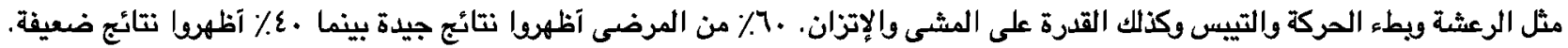

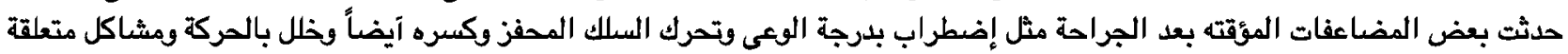
بالكلام وعدوى. الإستتاج: يعطى تدفيز المخ المميق لنواة تحت المهاد بإستخدام جراحة الإنحيز المجسم فى علاج مرض باركينسون مجهول السبب نتائج جيدة لمعظم المرضى الذين تم إختيارهم بعناية ودقة. 